\title{
LIVING KIDNEY DONOR EVALUATION FOR ALL CANDIDATES WITH NORMAL ESTIMATED GFR FOR AGE
}

François Gaillard ${ }^{1}$, Lola Jacquemont ${ }^{2 *}$, Hélène Lazareth $^{3 *}$, Laetitia Albano ${ }^{4}$, Benoit Barrou ${ }^{5}$, Nicolas Bouvier 6 , Mathias Buchler ${ }^{7}$, Dimitri Titeca-Beauport ${ }^{8}$, Lionel Couzi ${ }^{9}$, Michel Delahousse $^{10}$, Didier Ducloux ${ }^{11}$, Isabelle Etienne ${ }^{12}$, Luc Frimat ${ }^{13}$, Cyril Garrouste ${ }^{14}$, Denis Glotz ${ }^{15}$, Philippe Grimbert16, Marc Hazzan ${ }^{17}$, Alexandre Hertig18, Maryvonne Hourmant ${ }^{2}$, Nassim Kamar $^{19}$, Yann Le Meur ${ }^{20}$, Moglie Le Quintrec ${ }^{21}$, Christophe Legendre ${ }^{22}$, Valérie Moal ${ }^{23}$, Bruno Moulin ${ }^{24}$, Christiane Mousson ${ }^{25}$, Claire Pouteil-Noble26, Philippe Rieu27, Nacera Ouali28, Lionel Rostaing ${ }^{29}$, Antoine Thierry ${ }^{30}$, Fatouma Toure ${ }^{31}$, Jonathan Chemouny ${ }^{32}$, Pierre Delanaye ${ }^{33,34}$, Marie Courbebaisse ${ }^{35} \uparrow \&$ Christophe Mariat ${ }^{36} \dagger$

*Contributed equally to this work.

†Contributed equally to this work.

1 Department of Nephrology, Hôpital Bichat, Assistance Publique - Hôpitaux de Paris, Centre de recherche sur l'inflammation, INSERM UMR1149, CNRS EL8252, Laboratoire d'Excellence Inflamex, Université de Paris, Paris, France 2 Nephrology and Renal Transplantation Department, CHU Nantes, Nantes, France

3. Nephrology Department, Hôpital Européen Georges Pompidou, Paris, France

4. Nephrology and Renal Transplantation Department, Pasteur Hospital, Nice, France

5. Urology Department, Pitié-Salpêtrière, Paris, France

6. Nephrology, Dialysis, Transplantation Department, CHU Cote de Nacre, Caen University, Caen, France

7. Service de Néphrologie et Immunologie Clinique, CHU Tours, Université de Tours, Tours, France

8. Nephrology, Dialysis and Transplantation Department, University Hospital, Amiens, France

9. Nephrology, Transplantation and Dialysis, CHU Bordeaux, CNRS UMR 5164, Bordeaux University, Bordeaux, France

10. Nephrology, Dialysis and Renal Transplantation Department, Foch Hospital, Suresnes, France

11. Nephrology, Dialysis and Transplantation Department, CHU Besancon, Besancon, France

12. Nephrology Department, $\mathrm{CHU}$, Rouen, France

13. Nephrology, Dialysis and Transplantation Department, CHU, Nancy, France

14. Nephrology, Dialysis and Transplantation Department, CHU, Clermont Ferrand, France

15. Department of Nephrology and Renal Transplantation, Hôpital Saint Louis, Paris, France

16. Nephrology and Transplantation Department, UPEC University, Creteil, France

17. Nephrology Department, University Hospital, Lille, France

18. Nephrology and Transplantation, Hôpital Pitié Salpétrière, Paris, France

19. Department of Nephrology, Dialysis and Organ Transplantation, CHU Rangueil, INSERM U1043, IFRBMT, University Paul Sabatier, Toulouse, France 
Published in: Transplant international (2021), vol. 34, pp. 1123-1133

DOI: $10.1111 /$ tri.13870

Status : Postprint (Author's version)

20. Department of Nephrology and Renal Transplantation, CHU Brest, Brest, France

21. Nephrology, Transplantation and Dialysis Department, CHU Lapeyronie, and IRMB, INSERM U1183, Montpellier, France

22. Nephrology and Renal Transplantation Department, Hôpital Necker, Paris, France

23. Nephrology and Renal Transplantation, APHM, Marseille, France

24. Nephrology and Transplantation Department, University Hospital, Strasbourg, France

25. Nephrology Department, University Hospital, Dijon, France

26. Renal Transplantation Department, Hospices Civils de Lyon, Claude Bernard University, Lyon, France

27. Nephrology and Renal Transplantation Department, University Hospital, Reims, France

28. Nephrology and Renal Transplantation, Hôpital Tenon, Paris, France

29. Nephrology, Hemodialysis, Apheresis and Transplantation Department, University Hospital, Grenoble, France

30. Nephrology Department, University Hospital and Poitiers University, INSERM U1082, Poitiers, France

31. Nephrology, Dialysis and Renal Transplantation Department, CHU, Limoges, France

32. Nephrology, Dialysis and Transplantation Department, University Hospital, Rennes, France

33. Department of Nephrology-Dialysis-Transplantation, University of Liege (ULg CHU), Liege, Belgium

34. Department of Nephrology-Dialysis-Apheresis, Hôpital Universitaire Caremeau, Nimes, France

35. Department of Physiology, European Georges Pompidou Hospital, APHP, INSERM U1151, Paris University, Paris, France

36. Nephrology, Dialysis and Renal Transplantation Department, Hôpital Nord, CHU de Saint-Etienne, Jean Monnet University, COMUE Universite de Lyon, Lyon, France

KEYWORDS: age, estimated GFR, living kidney donors, post-donation GFR, screening

\section{ABSTRACT}

Multiple days assessments are frequent for the evaluation of candidates to living kidney donation, combined with an early GFR estimation (eGFR). Living kidney donation is questionable when eGFR is $<90 \mathrm{ml} / \mathrm{min} / 1.73 \mathrm{~m}^{2}$ (KDIGO guidelines) or $80 \mathrm{ml} / \mathrm{min} / 1.73 \mathrm{~m}^{2}$ (most US centres). However, age-related GFR decline results in a lower eGFR for older candidates. That may limit the number of older kidney donors. Yet, continuing the screening with a GFR measure increases the number of eligible donors. We hypothesized that in-depth screening should be proposed to all candidates with a normal eGFR for age. We compared the evolution of eGFR after donation between three groups of predonation eGFR: normal for age ( $S_{\text {age }}$ ) higher than 90 or $80 \mathrm{ml} / \mathrm{min} / 1.73 \mathrm{~m}^{2}$ ( $S_{90}$ and $S_{80}$, respectively); across three age groups $(<45,45-55,>55$ years) in a population of 1825 French living kidney donors with a median follow-up of 5.9 years. In donors younger than 45, postdonation eGFR, absolute- and relativeeGFR variation were not different between the three groups. For older donors, postdonation eGFR was higher in $S_{90}$ than in $S 80$ or Sage but other comparators were identical. Postdonation 
eGFR slope was comparable between all groups. Our results are in favour of in-depth screening for all candidates to donation with a normal eGFR for age.

\section{Introduction}

Evaluation of candidates to living kidney donation is a challenge for living kidney donor programmes since only $10-20 \%$ of candidates proceed to donation [1,2]. Most centres screen one candidate at a time and adopt a multiple-step screening (i.e. a progressive screening that consists in multiple days assessment) [3]. This approach limits the number of candidates who undergo in-depth evaluation to reduce the burden of the screening.

However, quality measures for living kidney donation include among others, equitability (number of transplantation performed) and timeliness (delay to assess suitability for living kidney donation) [4]. A higher number of transplantations and a shorter evaluation time of donors are both considered as positive markers. Yet, there exists inefficiencies in the donor evaluation process that may delay donation with significant consequences for the donor, the recipient and the healthcare system [5]. For the benefit of transplant recipients and living donors, all the barriers to screening candidates must be lifted.

Evaluation of glomerular filtration rate (GFR) is a potential bottleneck in the screening process, because a gold standard GFR measurement requires specific skills that may not be available everywhere. Hence, systematic and unanticipated GFR measurement may lengthen the screening process. Accordingly, Lentine et al. [6] suggested that streamlining GFR evaluation could be a potential solution. Such an approach implies that screening could be halted early (before GFR measurement) for some candidates. That would probably accelerate the screening process (improve timeliness). On the contrary, we demonstrated that an "in-depth" evaluation of renal function (a measure of GFR with an exogenous tracer) significantly increases the number of donors (increases equitability) [7]. The Kidney Disease Improving Global Outcomes (KDIGO) guidelines for living kidney donation provide a frame to ensure the safety of donation, maximize equitability and improve timeliness. For those guidelines, living kidney donation with an estimated GFR (eGFR) $<90 \mathrm{ml} / \mathrm{min} / 1.73 \mathrm{~m}^{2}$ is questionable and the decision to authorize donation must include an evaluation of lifetime-predicted end stage kidney disease risk (ESKD) [8]. Based on these estimators, (eGFR and ESKD risk) one may be tempted to halt the screening process, considering that further evaluation is futile (improve timeliness). In clinical practice in 2017, $74 \%$ of US centres use a decision-threshold of $80 \mathrm{ml} / \mathrm{min} / 1.73 \mathrm{~m}^{2}$ for living kidney donation [9].

Yet, physiological data show that GFR declines with ageing. Hence, eGFR of older candidates is more frequently $<90 \mathrm{ml} / \mathrm{min} / 1.73 \mathrm{~m}^{2}$ than it is for younger candidates. In other words, a single eGFR threshold of $90 \mathrm{ml} / \mathrm{min} / 1.73 \mathrm{~m}^{2}$, that is independent from age, may lead clinicians to question eligibility more frequently for older candidates than for younger candidates simply because GFR declines with ageing. In fact, older candidates are significant contributors to living kidney donation in France (30.7\% of donors $\geq 56$ years) [10] and in the USA (27.8\% of donors $\geq 50$ years) [11] and more importantly, the proportion of older donors increased significantly in both countries until 2017. This interpretation of eGFR independently from age may significantly 
reduce the pool of older donors because it may result in halting the screening more frequently for older candidates than for their younger counterparts.

For this reason, we hypothesized that screening should be continued for all candidates with a normal eGFR for age. To test our hypothesis, we considered the evolution of eGFR after donation, among effective living kidney donors, as a comparator of interest. First, postdonation GFR is a "safety belt" in case kidney disease would occur after donation [12-14]. Second, postdonation eGFR is an independent predictor of an increased ESKD risk after donation [15] and may thus serve as a proxy for long-term ESKD risk evaluation.

In this study, we compared postdonation eGFR and postdonation eGFR trajectories between three groups of donors defined by their predonation eGFR: normal for age, $\geq 90 \mathrm{ml} / \mathrm{min} / 1.73 \mathrm{~m}^{2}$ or $\geq 80 \mathrm{ml} / \mathrm{min} / 1.73 \mathrm{~m}^{2}$, in a cohort of French living kidney donors.

\section{Patients and method}

\section{COHORT}

We obtained data on all living kidney donors in France between 2006 and 2017 from the CRISTAL-donneur registry. Donor selection was performed in accordance with French guidelines for living kidney donation [16]. As this study is focused on postdonation eGFR, we included donors who had at least three creatinine measures after donation (of which at least $50 \%$ were performed after the first year after donation). Creatinine measures were collected during routine follow-up required by transplant centres. Donors whom baseline creatinine measurement was not available in the registry were excluded from the analysis. According to French law, retrospective studies on anonymized data do not require the authorization of an ethical committee [17]. Data on the whole renal transplantation activity in France are publicly available on the "Agence de Biomedecine" website [18]. Data are available from the authors upon reasonable request.

\section{CALCULATED VARIABLES}

The glomerular filtration rate was estimated (eGFR) with the Chronic Kidney Disease Epidemiology formula [19]. eGFR was calculated before donation and at all time points after donation. Absolute eGFR variation (expressed in $\mathrm{ml} / \mathrm{min} / 1.73 \mathrm{~m}^{2}$ ) corresponds to the difference between postdonation eGFR (at each time point of creatinine measure after donation) and predonation eGFR. Relative eGFR variation (expressed in \% of predonation eGFR) corresponds to the ratio of postdonation eGFR/predonation eGFR (at each time point of creatinine measure after donation). For each donor, the slope of eGFR variation, after donation, was calculated by linear regression. The body mass index (BMI) was calculated from height and weight as follows: weight/ height ${ }^{2}$ (height expressed in meters and weight in kilograms).

We divided donors in three age-groups $(<45,45-55$ and $>55$ years $)$ according to the percentage of cumulative incidence of ESKD in France, as previously reported [10,20]. Briefly, in France, $10 \%$ of incident ESKD patients are younger than $45 \%$ and $25 \%$ are younger than 55 years. 
Stratification by cumulative percentage of ESKD risk incidence, permits comparisons between countries with different age-distributed ESKD incidence [20].

\section{COMPARISON BETWEEN EGFR THRESHOLDS}

We defined three eGFR groups: (i) $S_{\text {age }}$ corresponds the group of donors with a predonation eGFR normal for age as defined by Pottel et al. [21] (eGFR $\geq 80.7 \mathrm{ml} / \mathrm{min} / 1.73 \mathrm{~m}^{2}$ for $<40$ years of age and $\geq 80.7^{*} 0.988^{\text {(Age- }}{ }^{40)} \mathrm{ml} / \mathrm{min} / 1.73 \mathrm{~m}^{2}$ for $\geq 40$ years of age). (ii) $S_{90}$ corresponds to the group of donors with a predonation eGFR $\geq 90 \mathrm{ml} / \mathrm{min} / 1.73 \mathrm{~m}^{2}$ (KDIGO guidelines [8]). (iii) $S_{80}$ corresponds to the group of donors with a predonation eGFR $\geq 80 \mathrm{ml} / \mathrm{min} / 1.73 \mathrm{~m}^{2}$ (reported to be used in the US population of donors [22]). It must be noted that a given donor may be included in different groups. For example, all donors with an eGFR $\geq 90 \mathrm{ml} / \mathrm{min} / 1.73 \mathrm{~m}^{2}$ belong to the group $S_{\text {age }}$ (because their eGFR is normal for age) and to the group $S_{90}$ (because their eGFR is superior to $90 \mathrm{ml} / \mathrm{min} / 1.73 \mathrm{~m}^{2}$ ).

At each time point of creatinine measure after donation, we compared, between the three groups, postdonation eGFR, absolute eGFR variation, relative eGFR variation. We counted the number of donors with a postdonation eGFR, 1 year after donation, lower than $50 \mathrm{ml} / \mathrm{min} / 1.73$ $\mathrm{m}^{2}$, between 50 and $70 \mathrm{ml} / \mathrm{min} / 1.73 \mathrm{~m}^{2}$ or higher than $70 \mathrm{ml} / \mathrm{min} / 1.73 \mathrm{~m}^{2}$. We chose these thresholds based on the publication by Massie et al. [15] showing different ESKD risk according to 6-month postdonation eGFR. We compared the slope of postdonation eGFR variation between the three groups. We counted the number of donors with a positive eGFR slope after donation (>1 ml/min/1.73 $\mathrm{m}^{2} /$ year), a null slope comprised between -1 and $+1 \mathrm{ml} / \mathrm{min} / 1.73 \mathrm{~m}^{2} /$ year and a negative slope lower than $-1 \mathrm{ml} / \mathrm{min} / 1.73 \mathrm{~m}^{2} /$ year.

Last, we compared the subgroup of donors with a normal eGFR for age but lower than 90 $\mathrm{ml} / \mathrm{min} / 1.73 \mathrm{~m}^{2}$ to the subgroup of donors with a normal eGFR for age but higher than 90 $\mathrm{ml} / \mathrm{min} / 1.73 \mathrm{~m}^{2}\left(S_{90}\right)$.

\section{STATISTICAL ANALYSES}

Baseline characteristics are presented as mean and standard deviation (SD). Statistical significance of the difference between groups was tested with the Kruskal-Wallis test. A p-value lower than 0.05 was considered as significant. All analyses were performed with $\mathrm{R}$ (R Core Team (2018). R: A language and environment for statistical computing. R Foundation for Statistical Computing, Vienna, Austria. URL https://www.R-project.org/.) with the use of the ggplot2 package [23]. The study complies with the STROBE requirement for retrospective studies.

\section{Results}

\section{DONORS}

A total of 4432 individuals donated a kidney between 2006 and 2017. Among them, 1825 were included in the analysis. The flow chart is presented in Fig. 1. Donors included in the analysis were slightly older $(51.0 \pm 11.1$ years vs. $49.0 \pm 11.6$; $\mathrm{P}<0.001)$ and their predonation eGFR 
was slightly lower $\left(94.5 \pm 14.2\right.$ vs. $\left.97.0 \pm 14.2 \mathrm{ml} / \mathrm{min} / 1.73 \mathrm{~m}^{2}, \mathrm{P}<0.001\right)$ than donors not included. Characteristics of donors included in the study are summarized in Table S1. The median follow-up of included donors was 5.9 years [IQR 4.08.0 years]. Mean age was different between the three eGFR $\quad$ groups $\left(47.7 \pm 10.7\right.$ years for $S_{90} ; 49.7 \pm 11.0$ years for $S_{80} ; 51.1 \pm$ 11.2 years for $\left.S_{\text {age; }} \mathrm{P}<0.001\right)$. In Table 1 , we summarize the characteristics of donors by ageand eGFR-group. Characteristics of donors were not different between eGFR-groups for those younger than 45. On the contrary, for donors older than 55, the Sage group, had a lower predonation eGFR compared to $S_{90}\left(87.1 \pm 10.1\right.$ vs. $\left.96.4 \pm 4.3 \mathrm{ml} / \mathrm{min} / 1.73 \mathrm{~m}^{2}, \mathrm{P}<0.001\right)$. Mean predonation eGFR of included and excluded donors, in each eGFR-group ( $S_{90}, S_{80}$ and $S_{\text {age }}$ ) are presented in Table S2.

\section{ONE-YEAR POSTDONATION EGFR}

We compared the distribution of 1-year postdonation eGFR (Table 2) between the three groups. The $S_{90}$ group had the lowest proportion of individuals with a 1-year postdonation eGFR $\leq 50$ $\mathrm{ml} / \mathrm{min} / 1.73 \mathrm{~m}^{2}$ and the highest proportion of donors with a 1-year postdonation eGFR $>70$ $\mathrm{ml} / \mathrm{min} / 1.73 \mathrm{~m}^{2}$, only in age groups " $45-55$ years" and " $>55$ years". For donors younger than 45 , the proportion of donors with a postdonation eGFR $\leq 50 \mathrm{ml} / \mathrm{min} / 1.73 \mathrm{~m}^{2}$ was similar between the three groups. When the population of donors was not stratified by age, the $S_{90}$ group had a higher 1-year postdonation eGFR at all time points after donation (Fig. 2a).

\section{POSTDONATION EGFR TRAJECTORIES}

The eGFR trajectories were similar between all groups, with a gradual increase overtime irrespective of the age category. Donors older than 45 in the $S_{90}$ group exhibited higher eGFR over years, compared to those in the $S_{80}$ and $S$ age groups. For donors younger than 45 , eGFR was not different between the three groups. Of note, we observed a plateauing eGFR for older donors in the $S_{90}$ group (Fig. 2b). Similar observations were made separately for female and male donors (Fig. S1a). 
Figure 1. Flow chart of donors included in the study

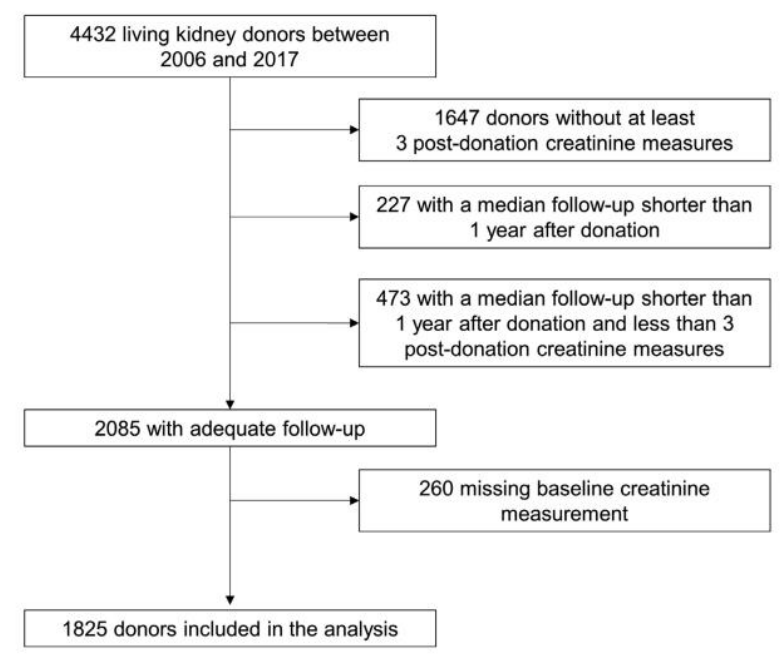

\section{ABSOLUTE AND RELATIVE EGFR VARIATION}

Absolute eGFR loss was significantly higher for $S_{90}$ than for $S_{80}$ or $S_{\text {age }}$ (Fig. 3a) especially for donors older than 45 . In the whole population not stratified by age, 5 -year absolute eGFR variation was $-31.4 \pm 10.6 \mathrm{ml} / \mathrm{min} / 1.73 \mathrm{~m}^{2},-30.3 \pm 10.6 \mathrm{ml} / \mathrm{min} / 1.73 \mathrm{~m}^{2},-28.8 \pm 10.8$ $\mathrm{ml} / \mathrm{min} / 1.73 \mathrm{~m}^{2}$ for $S_{90}, S_{80}$ and $S_{\text {age, }}$ respectively $(\mathrm{P}<0.01)$.

Relative eGFR loss was however not different between groups, regardless of age categories (Fig. $3 \mathrm{~b})$. As an example, 5 years after donation, relative eGFR loss was $31 \pm 10 \%$ for all groups. Similar observations were made separately for female and male donors (Fig. S1b, c).

\section{SLOPE OF EGFR VARIATION}

Slope of postdonation eGFR was calculated individually for each donor by linear regression on at least three creatinine measures after donation. On average, there were $5.2 \pm 2.2$ creatinine measures after donation in the $S_{90}$ group; $5.2 \pm 2.1$ creatinine measures and $5.3 \pm 2.2$ creatinine measures in $S_{80}$ and $S_{\text {age }}$ groups, respectively ( $P=0.33$, between groups). The mean follow-up was $6.1 \pm 2.5$ years in the $S_{90}$ group, $6.1 \pm 2.5$ years, $6.2 \pm 2.6$ years, for $S_{80}$ and $S_{\text {age, }}$ groups, respectively ( $P=0.82$, between groups).

Mean slope of postdonation eGFR was similar for all eGFR-groups and across all age-groups (Fig. 4). In the whole cohort, mean slopes were $+0.8 \pm 2.6 \mathrm{ml} / \mathrm{min} / 1.73 \mathrm{~m}^{2} /$ year; $+0.8 \pm 2.8$ $\mathrm{ml} / \mathrm{min} / 1.73 \mathrm{~m}^{2} /$ year; $+0.8 \pm 2.7 \mathrm{ml} / \mathrm{min} / 1.73 \mathrm{~m}^{2} /$ year; for $S_{90}, S_{80}$ and $S_{\text {age, }}$ respectively $(P=$ 0.89). Table 3 summarized the number of donors with a slope higher than $+1 \mathrm{ml} / \mathrm{min} / 1.73 \mathrm{~m}^{2}$ per year, lower than $-1 \mathrm{ml} / \mathrm{min} / 1.73 \mathrm{~m}^{2}$ per year or in-between (the 'stable' subjects), for each group. Proportion of donors in each category of eGFR slope was comparable between the three groups $(P=0.45)$. Characteristics of donors in each group of postdonation eGFR slope are summarized in Table 4.

Finally, donors with a normal eGFR for age but lower than $90 \mathrm{ml} / \mathrm{min} / 1.73 \mathrm{~m}^{2}$ had a positive and similar postdonation slope as compared to those in the $S_{90}$ group $(0.8 \pm 2.6 \mathrm{ml} / \mathrm{min} / 1.73$ 
Published in: Transplant international (2021), vol. 34, pp. 1123-1133

DOI: $10.1111 /$ tri.13870

Status : Postprint (Author's version)

$\mathrm{m}^{2}$ /year vs. $0.7 \pm 2.7 \mathrm{ml} / \mathrm{min} / 1.73 \mathrm{~m}^{2} /$ year, respectively $P=0.31$ ). Postdonation evolution of eGFR, absolute variation and relative variation are presented in Fig. S2. 
Table 1. Characteristics of included donors by age and eGFR groups.

\begin{tabular}{|c|c|c|c|c|c|c|c|c|c|}
\hline \multirow[b]{3}{*}{ eGFR-group } & \multicolumn{9}{|l|}{ Age group } \\
\hline & \multicolumn{3}{|l|}{$<45$ years } & \multicolumn{3}{|l|}{ 45-55 years } & \multicolumn{3}{|l|}{$>55$ years } \\
\hline & $S_{90}(n=431)$ & $S_{80}(n=470)$ & $S_{\text {age }}(n=471)$ & $S_{90}(n=429)$ & $S_{80}(n=562)$ & $S_{\text {age }}(n=627)$ & $S_{90}(n=292)$ & $S_{80}(n=501)$ & $S_{\text {age }}(n=667)$ \\
\hline Age (years) & $36.4(5.8)$ & $36.5(5.7)$ & $36.5(5.7)$ & $49.9(3.1)$ & $50(3.2)$ & $50.1(3.1)$ & $61.2(3.9)$ & $62(4.4)$ & $62.3(4.6)$ \\
\hline Female (\%) & $244(56.6)$ & $272(57.9)$ & $273(58.0)$ & $280(65.3)$ & 365 (64.9) & $403(64.3)$ & $193(66.1)$ & $322(64.3)$ & $439(65.8)$ \\
\hline Weight (kg) & $70.2(13.1)$ & $70.3(13.2)$ & $70.2(13.2)$ & $69.4(13.4)$ & $69.7(13.1)$ & $69.9(13.1)$ & $69.4(13)$ & $70.8(13.2)$ & 70.5 (13.1) \\
\hline Height (cm) & $169(8.8)$ & $169(8.7)$ & $169(8.7)$ & $166.7(9.1)$ & $167(8.8)$ & $167.1(8.7)$ & $165.8(8.2)$ & $166.5(8.5)$ & $166.4(8.4)$ \\
\hline BMI $\left(\mathrm{kg} / \mathrm{m}^{2}\right)$ & $24.5(3.7)$ & $24.5(3.7)$ & $24.5(3.7)$ & $24.9(3.9)$ & 24.9 (3.8) & $25(3.8)$ & $25.1(3.7)$ & $25.4(3.7)$ & $25.3(3.6)$ \\
\hline $\begin{array}{l}\text { Not related } \\
\text { to recipient }(\%)\end{array}$ & $140(32.5)$ & $156(33.2)$ & $156(33.1)$ & $153(35.7)$ & $212(37.7)$ & $237(37.8)$ & $129(44.2)$ & $216(43.1)$ & $288(43.2)$ \\
\hline Creatinine $(\mu \mathrm{mol} / \mathrm{l})$ & $68.3(11.9)$ & $69.5(12.3)$ & $69.5(12.3)$ & $64.7(9.8)$ & $67.9(11.3)$ & 69.9 (12.6) & $61.5(9.5)$ & $66.2(10.9)$ & $69.9(12.3)$ \\
\hline $\begin{array}{l}\text { Predonation eGFR } \\
\left(\mathrm{ml} / \mathrm{min} / 1.73 \mathrm{~m}^{2}\right)\end{array}$ & $108.7(9.5)$ & $106.8(11.1)$ & $106.7(11.2)$ & $101.5(5.7)$ & $97.6(8.6)$ & $95.3(10.6)$ & $96.4(4.3)$ & $91.7(6.7)$ & $87.1(10.1)$ \\
\hline $\begin{array}{l}\% \text { Of same individuals } \\
\text { as compared with } S_{90}\end{array}$ & $100 \%$ & $91.7 \%$ & $91.5 \%$ & $100 \%$ & $76.3 \%$ & $68.4 \%$ & $100 \%$ & $58.2 \%$ & $43.8 \%$ \\
\hline
\end{tabular}

\section{Table 2. Distribution of postdonation eGFR by age and eGFR groups}

\begin{tabular}{|c|c|c|c|c|c|c|c|c|c|}
\hline \multirow[b]{3}{*}{ eGFR-group } & \multicolumn{9}{|l|}{ Age group } \\
\hline & \multicolumn{3}{|l|}{$<45$ years } & \multicolumn{3}{|l|}{ 45-55 years } & \multicolumn{3}{|l|}{$>55$ years } \\
\hline & $S_{90}(n=431)$ & $S_{80}(n=470)$ & $S_{\text {age }}(n=471)$ & $S_{90}(n=429)$ & $S_{80}(n=562)$ & $S_{\text {age }}(n=627)$ & $S_{90}(n=292)$ & $S_{80}(n=501)$ & $S_{\text {age }}(n=667)$ \\
\hline $\begin{array}{l}\text { 1-year eGFR } \\
\left(\mathrm{ml} / \mathrm{min} / 1.73 \mathrm{~m}^{2}\right)\end{array}$ & $76.5(14.1)$ & $75.7(14.5)$ & $75.7(14.5)$ & $68.7(12.0)$ & $66.5(12.2)$ & $65.6(12.2)$ & $64.4(11.4)$ & $60.7(11.7)$ & $58.1(11.9)$ \\
\hline$P$-value* & - & 0.40 & 0.40 & - & 0.004 & $<0.001$ & - & $<0.001$ & $<0.001$ \\
\hline \multicolumn{10}{|l|}{$\begin{array}{r}\text { Class 1-year eGFR } \\
\left(\mathrm{ml} / \mathrm{min} / 1.73 \mathrm{~m}^{2}\right)\end{array}$} \\
\hline$<50$ & $1(0.2)$ & $2(0.4)$ & $2(0.4)$ & $15(3.5)$ & $33(5.9)$ & $45(7.2)$ & $20(6.8)$ & $74(14.8)$ & $159(23.8)$ \\
\hline $50-70$ & $153(35.5)$ & $181(38.5)$ & $182(38.6)$ & $230(53.6)$ & $329(58.5)$ & $377(60.1)$ & $193(66.1)$ & $332(66.3)$ & $411(61.6)$ \\
\hline$>70$ & $277(64.3)$ & $287(61.1)$ & $287(60.9)$ & $184(42.9)$ & $200(35.6)$ & $205(32.7)$ & $79(27.1)$ & $95(19)$ & $97(14.5)$ \\
\hline
\end{tabular}


Published in: Transplant international (2021), vol. 34, pp. 1123-1133

DOI: $10.1111 /$ tri.13870

Status : Postprint (Author's version)

Figure 2 Postdonation evolution of donors' eGFR between three different predonation eGFR groups (either $\geq 90\left(S_{90}\right) \geq$ or $\left.80\left(S_{80}\right) \mathrm{ml} / \mathrm{min} / 1.73 \mathrm{~m}^{2}\right)$ or normal for age ( $\left.S_{\text {age }}\right)$. (a) Evolution over time. Numbers above each time point represent the number of donors with available creatinine measure at the corresponding time point. ${ }^{* * * *} P<0.001$. (b) Evolution over time and according to donors' age. Grey zones represent the $95 \%$ confidence interval.
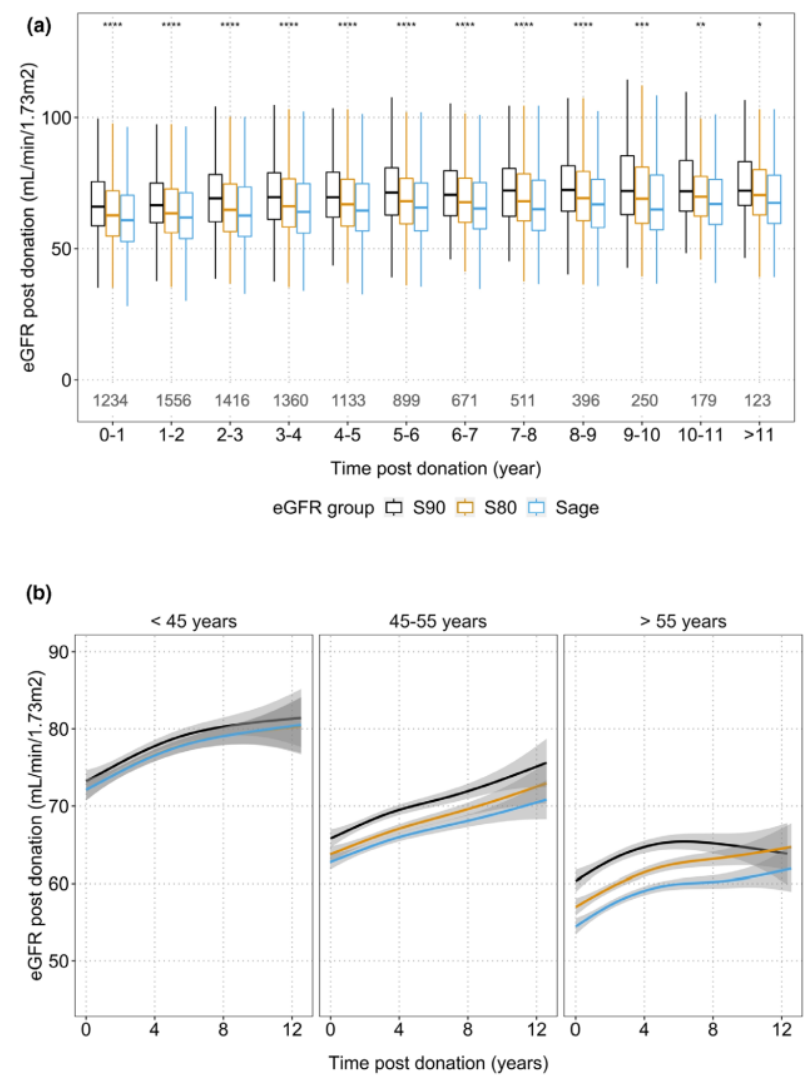

eGFR group $-\mathrm{S} 90=\mathrm{S} 80=\mathrm{Sage}$ 
Published in: Transplant international (2021), vol. 34, pp. 1123-1133

DOI: $10.1111 /$ tri.13870

Status : Postprint (Author's version)

Figure 3. Pre/Postdonation variation of donor's eGFR between three different predonation eGFR groups (either $\geq 90\left(S_{90}\right) \geq$ or $80\left(S_{80}\right) \mathrm{ml} / \mathrm{min} / 1.73 \mathrm{~m}^{2}$ ) or normal for age $\left(S_{\text {age }}\right)$. (a) Absolute variation over time and according to donors' age. (b) Relative variation over time and according to donors' age. Grey zone represents the $95 \%$ confidence interval.

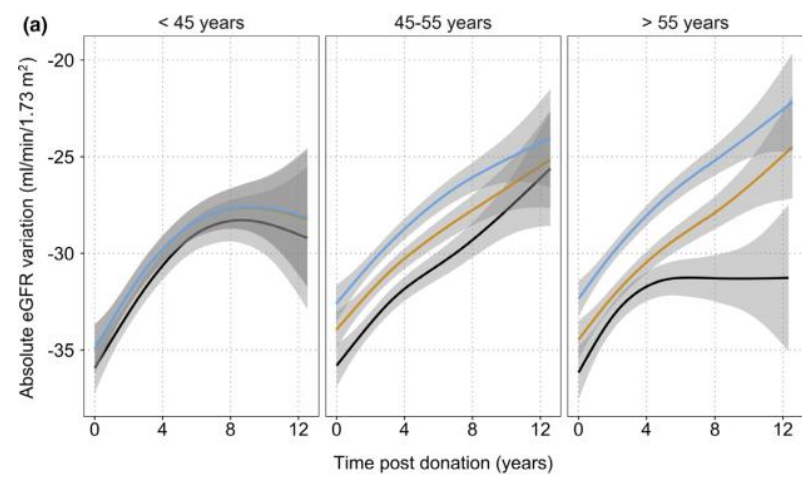

eGFR group $-\mathrm{S} 90=\mathrm{S} 80=$ Sage

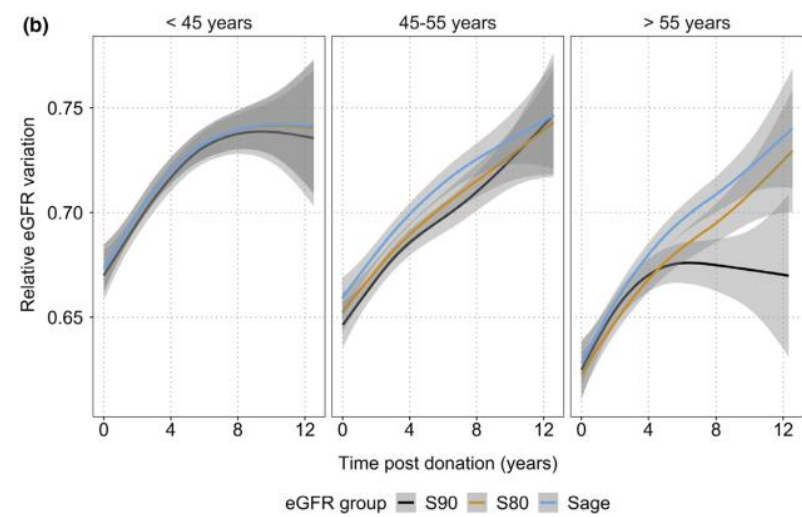

Figure 4. Postdonation slope of donors' eGFR between tthree different predonation eGFR groups (either $\geq 90\left(S_{90}\right)>$ or $\left.80\left(S_{80}\right) \mathrm{ml} / \mathrm{min} / 1.73 \mathrm{~m}^{2}\right)$ or normal for age ( $\left.S_{\text {age }}\right)$ and according to donors' age.

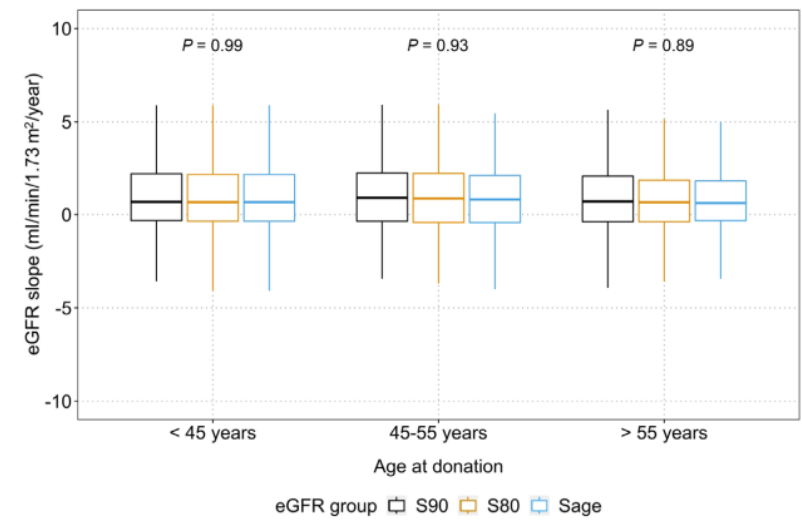


Table 3. Number of donors by postdonation eGFR slope class and predonation eGFR.

\begin{tabular}{llll}
\hline Postdonation & \multicolumn{3}{l}{ Predonation eGFR } \\
\cline { 2 - 4 } $\begin{array}{l}\text { eGFR slope } \\
\text { (ml/min/1.73 } \mathrm{m}^{2} / \text { year) }\end{array}$ & $\mathrm{S}=1152$ & $\mathrm{~S}=1533$ & $\mathrm{~S}=1765$ \\
\hline$>1$ & $519(45.1)$ & $677(44.2)$ & $753(42.7)$ \\
{$[-1 ; 1]$} & $444(38.5)$ & $611(39.9)$ & $741(42)$ \\
$<-1$ & $189(16.4)$ & $245(16)$ & $271(15.4)$ \\
\hline
\end{tabular}

The P-value of the Chi squared test is 0.45 .

Table 4. Characteristics of donors according to eGFR slope.

\begin{tabular}{|c|c|c|c|c|}
\hline & \multicolumn{3}{|c|}{ eGFR slope $\left(\mathrm{ml} / \mathrm{min} / 1.73 \mathrm{~m}^{2} /\right.$ year $)$} & \multirow[b]{2}{*}{$P$-value } \\
\hline & $<-1$ & {$[-1 ; 1]$} & $>1$ & \\
\hline Number of donors & 275 & 768 & 782 & - \\
\hline Female (\%) & $187(68.0)$ & $486(63.3)$ & $488(62.4)$ & 0.24 \\
\hline Age (years) & $50.3(11.0)$ & $51.5(11.1)$ & $50.8(11.2)$ & 0.26 \\
\hline Weight (kg) & $70.2(13.7)$ & $70.5(13.0)$ & $69.9(13.1)$ & 0.67 \\
\hline Height $(\mathrm{cm})$ & $166.9(8.5)$ & $167.3(8.6)$ & $167.4(8.7)$ & 0.67 \\
\hline $\mathrm{BMl}\left(\mathrm{kg} / \mathrm{m}^{2}\right)$ & $25.1(3.8)$ & $25.1(3.7)$ & $24.9(3.7)$ & 0.38 \\
\hline Creatinine $(\mu \mathrm{mol} / \mathrm{l})$ & $68.4(13.0)$ & $71.8(13.3)$ & $70.3(13.5)$ & $<0.001$ \\
\hline Not related to recipient (\%) & $110(40.0)$ & $290(37.8)$ & $303(38.7)$ & 0.79 \\
\hline Predonation eGFR $\left(\mathrm{ml} / \mathrm{min} / 1.73 \mathrm{~m}^{2}\right)$ & $96.1(13.1)$ & $92.8(14.3)$ & $95.2(13.9)$ & $<0.001$ \\
\hline Postdonation creatinine measures $(\mathrm{N})$ & $4.6(1.7)$ & $5.9(2.3)$ & $5.0(2.1)$ & $<0.001$ \\
\hline Median follow-up (years) & $2.9(1.3)$ & $3.8(1.6)$ & $3.1(1.5)$ & $<0.001$ \\
\hline
\end{tabular}

BMI, body mass index.

Data are presented as mean and standard deviation. eGFR are calculated with the CKD-EPI formula

\section{DISCUSSION}

Five years after donation, relative eGFR variation (as a surrogate of the compensatory response) was not different between eGFR groups. Similarly, we found that regardless of age, postdonation eGFR slopes and their distributions were similar between eGFR-groups. On the contrary, one year after donation, eGFR was different between the three groups only for donors older than 45 . Similarly, overtime after donation, the S90 group had a higher eGFR only for donors older than 45. These observations on postdonation data suggest that in-depth evaluation, including GFR measurement, should be proposed to all individuals with a normal eGFR for age.

We reported that older age was associated with a lower predonation mGFR and eGFR [7,24]. In the present study, we extend this observation to postdonation eGFR: donors with the lowest postdonation eGFR are also the oldest. Given a shorter remaining lifetime exposure to ESKD risk, older donors may be at much lower risk of ESKD than their younger counterparts [25]. This has already been confirmed for young black donors in the United States who are at higher risk compared to older donors [26]. The lower eGFR one year after donation for the Sage group compared to the $\mathrm{S} 90$ group, may be a direct consequence of age-differences between groups. This observation puts emphasis on age as a determinant of pre- and postdonation eGFR.

Yet, the association between lower postdonation eGFR and increased ESKD risk still holds true after adjusting on donor' age [15] as reported by Massie et al. In this study, median donors' age was 5 to 10 years lower than in our study and maximum follow-up was 10 years. Remarkable it 
may be among living kidney donor studies, such a follow-up may not capture all ESKD events, especially for younger donors who are at very low ESKD risk at donation. In other words, it takes longer for a young donor to develop ESKD than it takes for an older donor. As exampled by Steiner, a follow-up of 40 years would be required to observe all the expected cases of ESKD among donors younger than 35 in the United States [25]. While we do not question that low postdonation eGFR is associated with higher risk of subsequent ESKD, we believe that available data underestimate the magnitude of the association among younger donors. If so, a lower eGFR after donation, among older donors, may not reflect the same amount of donation-attributed ESKD risk as a lower eGFR after donation among younger donors. Reassuringly, we observed no differences between postdonation eGFR among donors younger than 45 in the three groups.

The compensatory response and eGFR slope in the $S_{\text {age }}$ group are not different from those observed in the $S_{90}$ group. This is in agreement with the observation by Lam et al. [27] comparing eGFR evolution after living kidney donation across different predonation eGFR groups. Likewise, the proportion of donors with a positive or a negative postdonation eGFR slope was similar between the three groups, even though donors were younger in the $S_{90}$ group than in the $S_{\text {age }}$ group. Those donors with a negative slope are potentially at the highest risk of developing ESKD and would need to be thoroughly phenotyped. We were, however, unable to identify any baseline characteristic that was significantly associated with a negative eGFR slope after donation (Table 4).

Our study has limitations. As a retrospective study, selection bias is possible. Only a fraction of donors was included and we observed that the population of donors with a follow-up was not statistically identical to the group of donors who did not have a follow-up. Yet, differences between populations are of little clinical relevance and the difference in predonation eGFR between eGFR groups tended to be higher for included donors than for excluded donors, suggesting that including the whole population may have reduced observed differences between groups (that would not have changed our conclusion). Second, the number of included donors was mainly limited by our expectations on post-donation creatinine measures. To provide robust results on postdonation eGFR trends, we included only donors without missing data, with at least 3 creatinine measures after donation and for whom at least $50 \%$ of creatinine measures were available at least 1 year after donation. By doing so, we can provide postdonation eGFR slopes calculated with a mean of 5.2 measures of creatinine after donation. Unfortunately, blood pressure, albuminuria and proteinuria are not available in the registry. Similarly, we could not evaluate the impact of birth weight, fasting blood glucose, ethnicity or renal volume on postdonation eGFR as those data are absent from the registry. These factors may be associated with a declining eGFR postdonation and may have different distribution between groups. Yet, differences between individuals are likely to be modest because all participants were in sufficiently good health to donate a kidney. Of note, because of the absence of 'ethnicity' in the registry we did not correct eGFR for donors of African ancestry. The follow-up after donation was limited as data range from 2006 to 2017. It is possible that longer follow-up would have resulted in different eGFR slopes after donation as suggested by a recent study by Kasiske et al. who found a positive GFR slope between 6 months and 3 years after donation, but a slightly negative measured GFR slope between 3 and 9 years [28]. We also cannot explain the eGFR plateau observed for older donors in the $\mathrm{S} 90$ group, while other age-groups experience a 
continuous eGFR increase. It is possible that those donors already had a "hyper-filtration" before donation that limited eGFR increase after donation [29].

Differences in postdonation eGFR between $S_{\text {age }}$ and $S_{90}$ were not significant for donors younger than 45. For older donors, an age-adapted interpretation of eGFR resulted in lower postdonation eGFR but comparable compensatory response to nephrectomy between groups. More importantly, the proportion of donors with a negative eGFR slope was comparable between the three groups.

We focused this study on eGFR interpretation as a potential barrier to in-depth screening of candidates to donation. An eGFR below 90 or $80 \mathrm{ml} / \mathrm{min} / 1.73 \mathrm{~m}^{2}$ is questionable for living kidney donation and may prematurely halt the screening for would-be healthy donors when considering age in the interpretation of eGFR [7]. We do not state that all candidates with a normal eGFR for age would be eligible to donation. We believe that measured GFR is the gold standard for the evaluation of predonation GFR for living kidney donors and this study was not designed to evaluate the safety of a screening based on eGFR. However, eGFR is unambiguously part of the screening of all candidates to donation. Our results show that candidates with a normal eGFR for age who become effective kidney donors do not have a poorer postdonation renal function as compared with those having a predonation eGFR $>90 \mathrm{ml} / \mathrm{min} / 1.73 \mathrm{~m}^{2}$. This study demonstrates that, among all candidates with a normal eGFR for age, there exists a pool of individuals that would make healthy living kidney donors. In line with this observation, a one day donor assessment model, that potentially lifts the 'eGFR-related' barrier to in-depth screening, is associated with an increase in living kidney donation [30].

In conclusion, donors with a normal eGFR for age $\left(S_{\text {age }}\right)$ are older than donors with an eGFR $>90$ $\mathrm{ml} / \mathrm{min} / 1.73 \mathrm{~m}^{2}\left(S_{90}\right)$ and differences in postdonation eGFR are partly attributable to this agedifference. Other comparators (slope, relative eGFR, distribution of slopes) were not different between groups. Our results are in favour of in-depth screening for all candidates to donation with a normal eGFR for age.

\section{STATEMENT}

The results from this study have not been published elsewhere.

\section{AUTHORSHIP}

All the authors contributed to data collection. FG designed the study, wrote the manuscript and performed statistical analysis. FG, PD, MC and CM designed the study and wrote the manuscript. All the authors reviewed the manuscript and approved it in its final form.

\section{FUNDING}

The authors have declared no funding.

\section{CONFLICT OF INTEREST}

The authors declare no conflict of interest. 


\section{ACKNOWLEDGEMENT}

F.G would like to thank Aurelie Deshayes (Agence de la Biomédecine) for data quality management.

\section{SUPPORTING INFORMATION}

Additional supporting information may be found online in the Supporting Information section at the end of the article.

Figure S1. (a) Postdonation evolution of donors' eGFR between three different predonation eGFR groups (either $\geq 90\left(S_{90}\right) \geq$ or $\left.80\left(S_{80}\right) \mathrm{ml} / \mathrm{min} / 1.73 \mathrm{~m}^{2}\right)$ or normal for age $\left(S_{\text {age }}\right)$. (b) Absolute eGFR variation after donation between three different predonation eGFR groups (either $\geq 90\left(S_{90}\right) \geq$ or $\left.80\left(S_{80}\right) \mathrm{ml} / \mathrm{min} / 1.73 \mathrm{~m}^{2}\right)$ or normal for age $\left(S_{\text {age }}\right)$. (c) Relative eGFR variation after donation (as compared to predonation eGFR) between three different predonation eGFR groups (either $\geq 90\left(S_{90}\right) \geq$ or $80\left(S_{80}\right) \mathrm{ml} / \mathrm{min} / 1.73 \mathrm{~m}^{2}$ ) or normal for age $\left(S_{\text {age }}\right)$.

Figure S2. For donors with a normal eGFR for age at donation, comparisons between those with an eGFR higher or lower than $90 \mathrm{ml} / \mathrm{min} / 1.73 \mathrm{~m}^{2}$.

Table S1. Characteristics of donors included in the analysis.

Table S2. Mean pre-donation eGFR in each eGFR-group. 


\section{References}

\section{REFERENCES}

1. Moore DR, Feurer ID, Zaydfudim V, et al. Evaluation of living kidney donors: variables that affect donation. Prog Transplant Aliso Viejo Calif 2012; 22: 385.

2. Lapasia JB, Kong S, Busque S, Scandling JD, Chertow GM, Tan JC. Living donor evaluation and exclusion: the Stanford experience. Clin Transplant 2011; 25: 697.

3. Habbous S, Woo J, Lam NN, et al. The efficiency of evaluating candidates for living kidney donation: a scoping review. Transplant Direct 2018; 4: e394.

4. Knoll GA, Fortin M-C, Gill J, et al. Measuring quality in living donation and kidney transplantation: moving beyond survival metrics. Kidney Int 2020; 98: 860.

5. Habbous S, McArthur E, Sarma S, et al. Potential implications of a more timely living kidney donor evaluation. Am J Transplant 2018; 18: 2719.

6. Lentine KL, Levey AS, Segev DL. Integrated risk assessment versus age-specific GFR thresholds for living donor candidate evaluation. Transplantation 2020; 104: 2464.

7. Gaillard F, Courbebaisse M, Kamar N, et al. Impact of estimation versus direct measurement of predonation glomerular filtration rate on the eligibility of potential living kidney donors. Kidney Int 2019; 95: 896.

8. Lentine KL, Kasiske BL, Levey AS, et al. KDIGO clinical practice guideline on the evaluation and care of living kidney donors. Transplantation 2017; 101(8 Suppl 1): S7.

9. Garg N, Lentine KL, Inker LA, et al. The kidney evaluation of living kidney donor candidates: US practices in 2017. Am J Transplant 2020; 20: 3379.

10. Gaillard F, Jacquemont L, Roberts V, et al. Temporal trends in living kidney donation in France between 2007 and 2017. Nephrol Dial Transplant 2021; 36: 730.

11. Al Ammary F, Bowring MG, Massie AB, et al. The changing landscape of live kidney donation in the United States from 2005 to 2017. Am J Transplant 2019; 19: 2614.

12. Steiner RW. The risks of living kidney donation. N Engl J Med 2016; 374: 479.

13. Steiner RW. Amending a historic paradigm for selecting living kidney donors. Am J Transplant 2019; 19: 2405.

14. Steiner RW. "You can't get there from here": critical obstacles to current estimates of the ESRD risks of young living kidney donors. Am J Transplant 2019; 19: 32.

15. Massie AB, Holscher CM, Henderson ML, et al. Association of early postdonation renal function with subsequent risk of end-stage renal disease in living kidney donors. JAMA Surg 2020; 155: e195472.

16. Thuong M. Prélèvement et greffe rénale à partir de donneur vivant. Recommandations formalisées d'experts-texte court. Néphrol Thér 2010; 6: 138.

17. Délibération $N^{\circ}$ 2018-155 Du 3 Mai 2018 Portant Homologation de La Méthodologie de Reference Relative Aux Traitements de Données à Caractère Personnel Mis En CEuvre Dans Le Cadre Des Recherches n'impliquant Pas La Personne Humaine, Des Etudes et Evaluations Dans Le Domaine de La Sante (MR- 
004). Accessed April 14, 2019. https://www.legifrance.gouv.fr/affichTexte.do?cidTexte=JORF TEXT000037187498\&categorieLien=id.

18. Agence de la biomédecine - Le rapport annuel médical et scientifique 2017. Accessed May 19, 2019. https://www.agence-biomedecine.fr/annexes/bilan2017/ donnees/organes/06-rein/synthese.htm.

19. Levey AS, Stevens LA, Schmid CH, et al. A new equation to estimate glomerular filtration rate. Ann Intern Med 2009; 150: 604.

20. Gaillard F, Fournier C, Legendre C. Lifetime ESKD risk stratification for living kidney donor studies. Am J Transplant 2019; 19: 2658.

21. Pottel H, Delanaye P, Weekers L, et al. Age-dependent reference intervals for estimated and measured glomerular filtration rate. Clin Kidney J 2017; 10: 545.

22. Ibrahim HN, Foley R, Tan LiPing, et al. Long-term consequences of kidney donation. N Engl J Med 2009; 360: 459 .

23. Wickham H, Chang W, Henry L, et al. Ggplot2: create elegant data visualisations using the grammar of graphics, 2019. Accessed June 1, 2019. https:// CRAN.R-project.org/package=ggplot2.

24. Gaillard F, Courbebaisse M, Kamar N, et al. The age-calibrated measured glomerular filtration rate improves living kidney donation selection process. Kidney Int 2018; 94: 616.

25. Steiner RW. "Normal for now" or "at future risk": a double standard for selecting young and older living kidney donors. Am J Transplant 2010; 10: 737.

26. Wainright JL, Robinson AM, Wilk AR, Klassen DK, Cherikh WS, Stewart DE. Risk of ESRD in prior living kidney donors. Am J Transplant 2018; 18: 1129.

27. Lam NN, Lloyd A, Lentine KL, et al. Changes in kidney function follow living donor nephrectomy. Kidney Int 2020; 98: 176.

28. Kasiske BL, Anderson-Haag TL, Duprez DA, et al. A prospective controlled study of metabolic and physiologic effects of kidney donation suggests that donors retain stable kidney function over the first nine years. Kidney Int 2020; 98: 168.

29. Steiner RW. Increased single-nephron GFR in normal adults: too much of a good thing ... or maybe not? Am J Kidney Dis 2018; 71: 312.

30. Graham JM, Courtney AE. The adoption of a one-day donor assessment model in a living kidney donor transplant program: a quality improvement project. Am J Kidney Dis 2018; 71: 209 